\title{
Hip Joint Ligaments, a Cadaver Imaging Study for Education
}

\author{
Ligamentos de Cadera, un Estudio Cadavérico Imagenológico para Educación
}

\author{
Dong Sun Shin*; Sung Bae Hwang**; Jin Seo Park***; Hyung Seon Park****; \\ Sangho Lee ${ }^{* * * * *}$; Seung-Bock Lee ${ }^{* * * * *}$ \& Min Suk Chung ${ }^{* * * * * *}$
}

SHIN, D. S.; HWANG, S. B.; PARK, J. S.; PARK, H. S.; LEE, S.; LEE, S-B. \& CHUNG, M. S. Hip joint ligaments, a cadaver imaging study for education. Int. J. Morphol., 32(3):822-828, 2014.

SUMMARY: The stereoscopic morphology of the iliofemoral, pubofemoral, and ischiofemoral ligaments in hip joint is hard to understand, either in anatomy books or from cadaver dissection. To aid in understanding, three-dimensional models were built from the sectioned images of cadaver hip, which demonstrate fine components better than CTs and MRIs. In the female data of Visible Korean project, the ligaments and neighboring structures were recognized and outlined in detail. Successively, the outlines were stacked and reconstructed to manufacture their surface models by using the sophisticated computer method. The surface models were overlapped with the original sectioned images, which enhanced comprehension of the hip joint anatomy. With the surface models, hip joint was hyperextended to suggest the function of the ligaments. The graphic data of the surface reconstructed hip ligaments are expected to be the source of interactive simulators for anatomy and surgery of the hip joint.

KEY WORDS: Hip joint; Ligaments; Visible Human Projects; Cross-sectional anatomy; Three-dimensional imaging.

\section{INTRODUCTION}

Hip joint movement is restricted by the three fundamental ligaments, iliofemoral ligament splitting into transverse and descending parts, pubofemoral ligament, and ischiofemoral ligament (Moore et al., 2014). The arrangement and resultant function of the ligaments are learned by medical students and orthopedic surgeons, especially due to the current hip joint operations, such as surgical hip replacement. However, the ligaments' stereoscopic configuration cannot be readily recognized in the anatomy atlases. The details of the ligaments, not sufficiently identified in the computerized tomographs (CTs) and magnetic resonance images (MRIs), are discernible in the sectioned cadaver images, using high resolution and real body color. After identification and demarcation, human body components are surface reconstructed to assemble three-dimensional (3D) models with potential applicability in many areas (Park et al., 2007; Shin et al., 2009a, 2009b, 2011a; Jang et al., 2011).

The purpose of the present study was to demonstrate the morphological characteristics of the hip joint ligaments in the sectioned images and 3D surface models. Therefore, up-to-date sectioned images of a female left pelvis were examined to discover the hip joint constituents. In addition, the ligaments, bones, and other structures were outlined and reconstructed using advanced computer techniques on the suitable software packages.

\section{MATERIAL AND METHOD}

For a new trial of Visible Korean project, the donated cadaver of a 43-year-old Korean female, $1.52 \mathrm{~m}$ in height and weighing $54 \mathrm{~kg}$, was selected. The pelvis was separated from the cadaver, embedded and milled at $0.1 \mathrm{~mm}$ intervals. All sectioned surfaces were photographed to create horizontal sectioned images $(0.1 \mathrm{~mm}$ sized pixels, 48 bit color, tag image file format (TIFF)) (Park et al., 2008; Hwang et al., 2010).

From the total sectioned images, we selected 251 images ( $1 \mathrm{~mm}$ intervals) from the superior end of the hip bone to the body of the femur. The main frame of our interest

* Department of Orthopaedic Biomaterial Science, Osaka University Graduate School of Medicine, Osaka, Japan.

** Department of Physical Therapy, Kyungbuk College, Youngju, Republic of Korea.

*** Department of Anatomy, Dongguk University College of Medicine, Gyeongju, Republic of Korea.

***** Korea Institute of Science and Technology Information, Daejeon, Republic of Korea.

****** Department of Anatomy, Ajou University School of Medicine, Suwon, Republic of Korea. 
was the sacrum, left hip bone, and left femur, beyond which, excessive margins were cropped. The sectioned images were opened on Photoshop CS5 version 12 (Adobe
Systems, Inc., San Jose, CA) to be saved as Photoshop document (PSD) files.

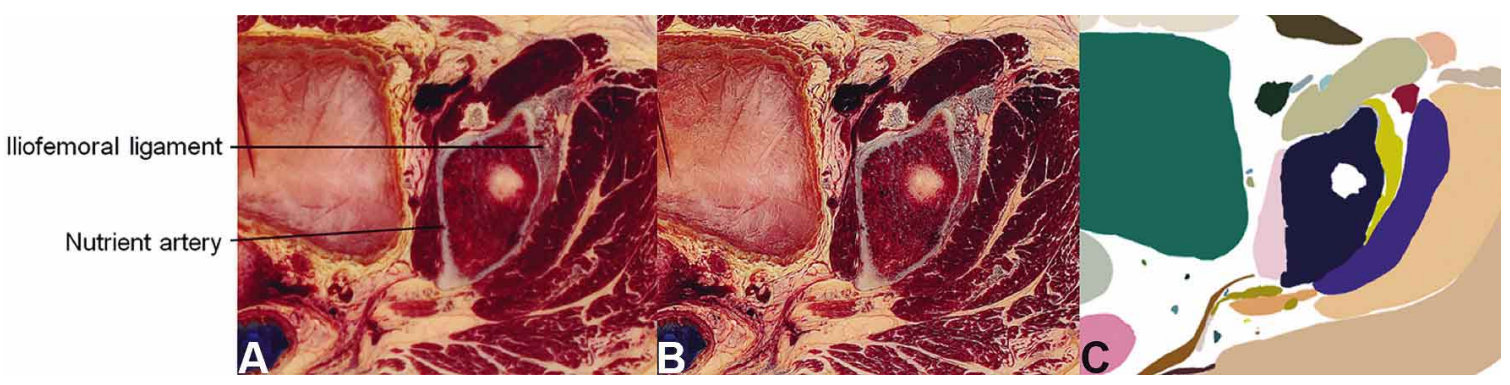

Fig. 1. Sectioned and color-filled images. By filtering, the original sectioned image (A) is converted into one, where the ligament borders get more definite (B) to assist delineation (C).

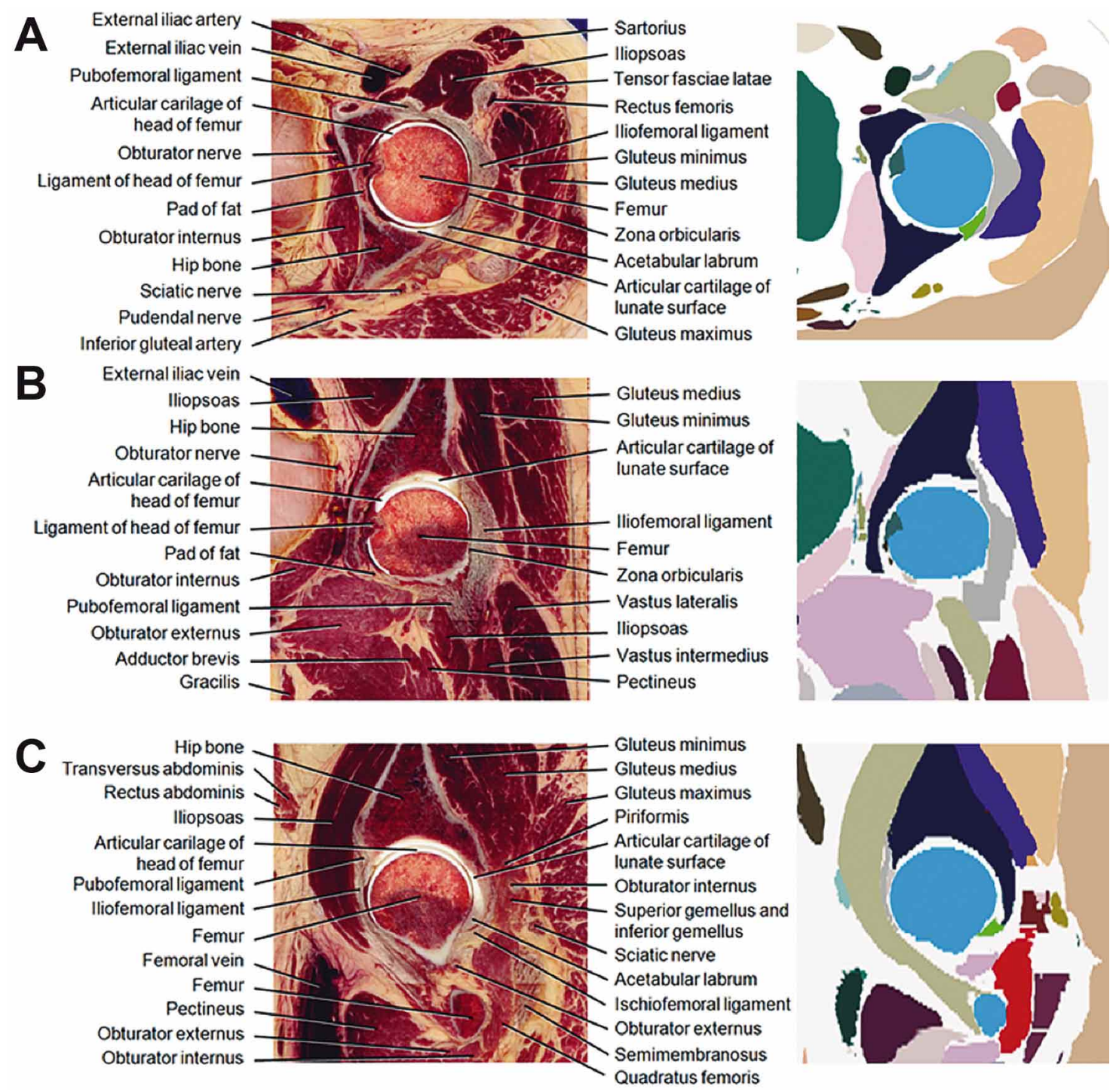

Fig. 2. Sectioned images with plenty of hip joint structures annotated (left column) and corresponding color-filled images (right column). The horizontal (A), coronal (B), and sagittal (C) planes, passing the center of head of femur, are selected. 
We identified and outlined bones (sacrum, hip bone, and femur), ligaments (iliofemoral, pubofemoral, and ischiofemoral), acetabular labrum, muscles, nerves, arteries, and veins in the left side of cadaver. To enhance automation of demarcation, sectioned images (Fig. 1A) were "sharpen" filtered on Photoshop (Fig. 1B). The structures' contours were then drawn using the procedures we developed on Photoshop in previous studies (Park et al., 2005, 2009; Shin et al., 2012a, 2012b). Most structures were delineated manually, using the "lasso" tool. But apparent ones could be demarcated semi-automatically with the "quick selection" tool. After segmentation was completed, the outlines were filled with specific colors for the individual structures; the color-filled images were saved as bit map (BMP) files (Fig. 1C).

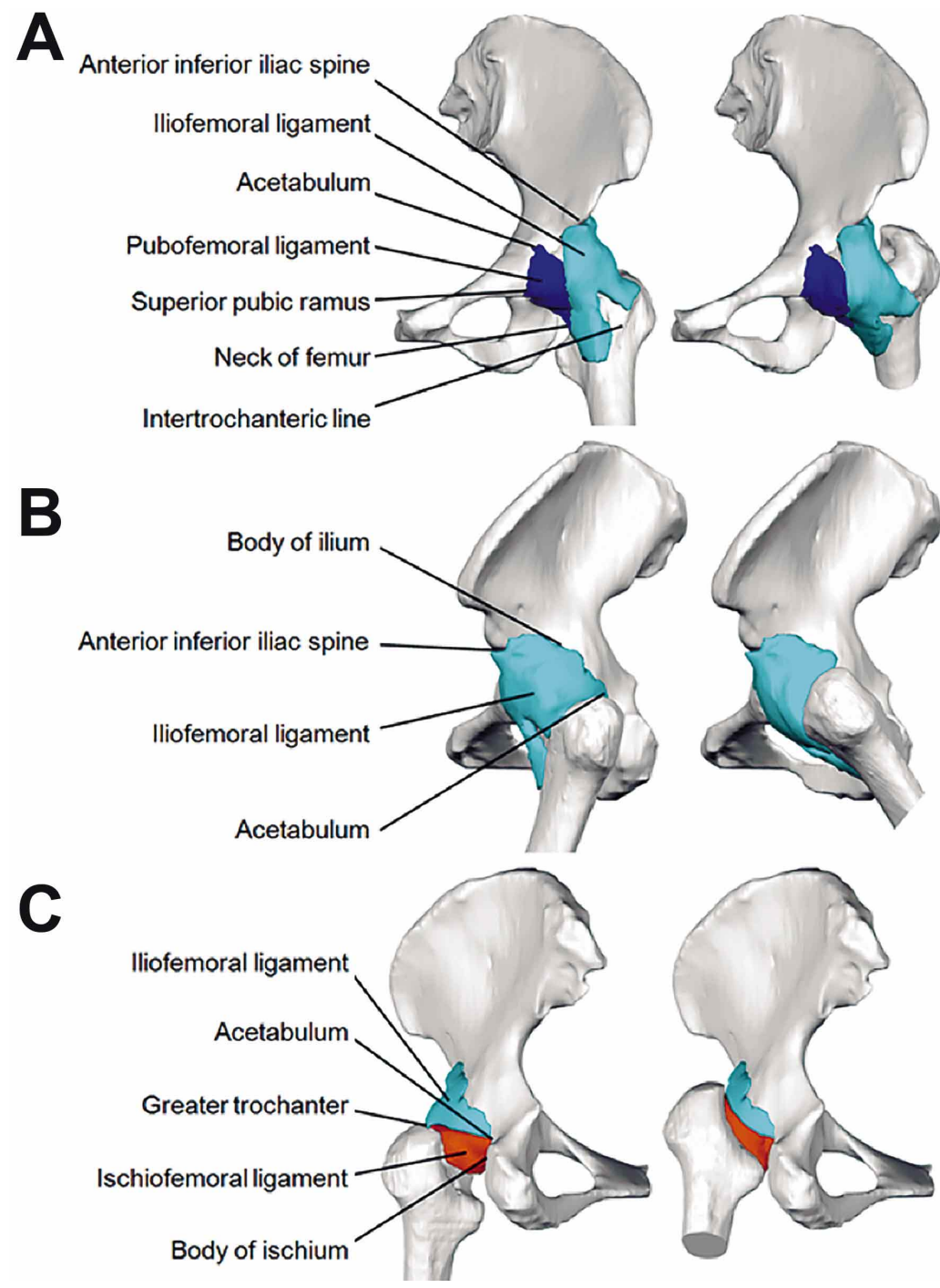

Fig. 3. Surface models of the ligaments and bones of the left hip joint (left column) and those after hyperextension (70 degrees) (right column) in the anterior view (A), lateral view (B), posterior view (C).
On our own composed software, both sectioned images and color-filled images were stacked and were vertically cut to generate coronal and sagittal planes. In any horizontal, coronal, sagittal planes, a couple of sectioned and color-filled images deservedly corresponded to each other. The conformity facilitated labeling on the sectioned images (Fig. 2).

Mimics version 10.01 (Materialise, Leuven, Belgium) was utilized for surface reconstruction of colorfilled images of the hip joint. With the brightness of the color, the Mimics software recognized and clustered the serial outlines of each structure. After stacking the outlines, surface reconstruction of all structures was achieved at the same time. The concurrently built surface models were divided into a number of models of independent constituents and saved as Mimics (MCS) files that retained the structures' own locational information (Lee et al., 2008; Benkhadra et al., 2009; Storck et al., 2010). In each surface model, the accumulated outlines were removed and triangular surfaces were appropriately reduced in number. Inadequate surface models, resulting from incorrect outlining, were revised by anatomists (Park et al., 2007).

On Mimics, surface models of the bones and ligaments were diversely colored to distinguish the adjacent structures (Fig. 3). Combination of the bones and muscles, accompanied by nerves innervating the muscles, were selected for display (Fig. 4).

Mimics enabled the surface models of the bones and ligaments either to be sectioned off in sequence or to be added in reverse sequence. Simultaneously, the sectional planes of surface models can be covered by the outlined images, color-filled images or sectioned images. The real sectioned images were derived from the volume model, constructed with the same software, Mimics (Fig. 5).

On the Mimics, the surface models of bones and ligaments were saved as stereolithography (STL). The file format (STL) was converted into the Maya binary (MB) by Maya version 2012 (Autodesk, Inc., San Rafael, CA). Using a "smooth bind" function of the Maya, the femur was 


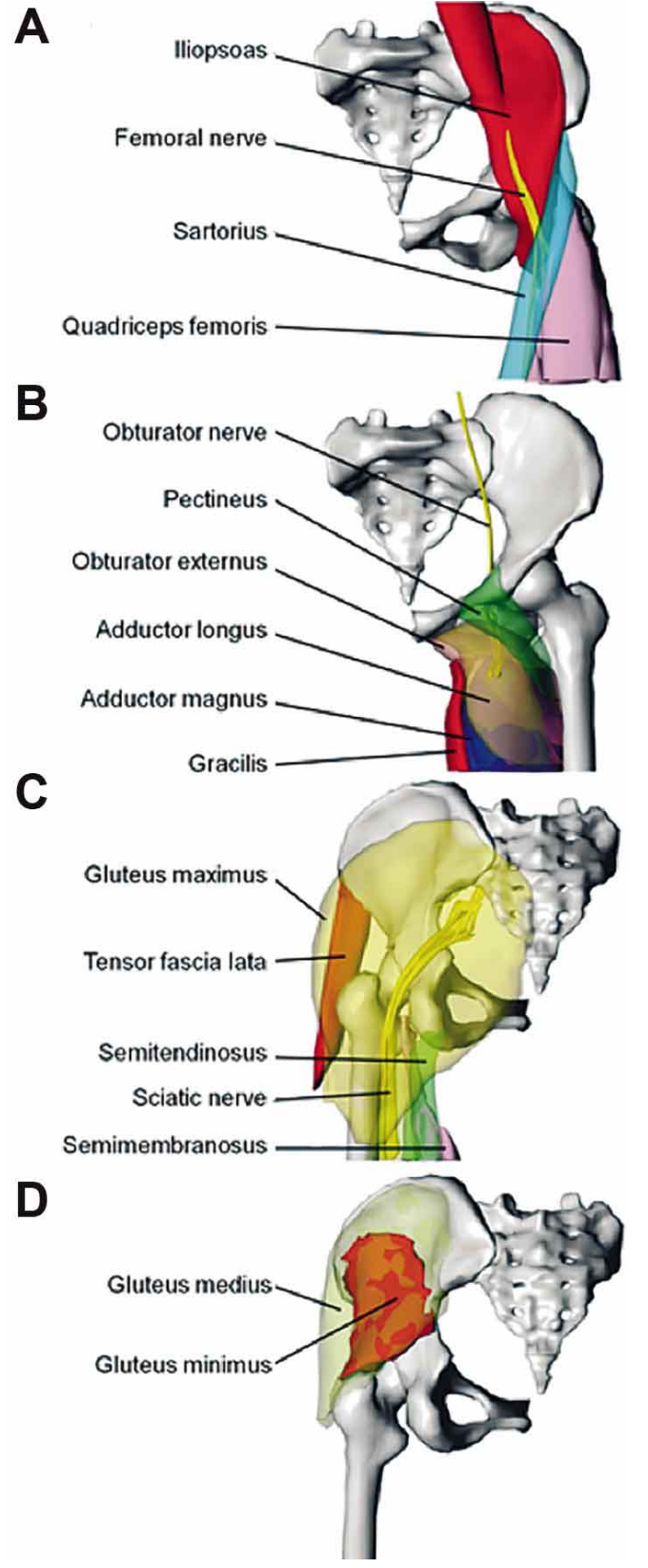

Fig. 4. Surface models of the hip joint muscles and their innervating nerves. Muscles are roughly categorized into the flexors (A) and adductors (B) shown in the anterior view; the extensors (C) and abductors (D) shown in the posterior view.

hyperextended to show the elongation of the ligaments. The software prevented the ligaments from being overlapped by the bones to be as realistic as possible. The 70 degrees of hyperextension was suitably decided to depict the ligaments' morphologic alteration (Fig. 3). It was also attempted to simplify the three ligaments' morphology for clarification of their roles (Fig. 6).

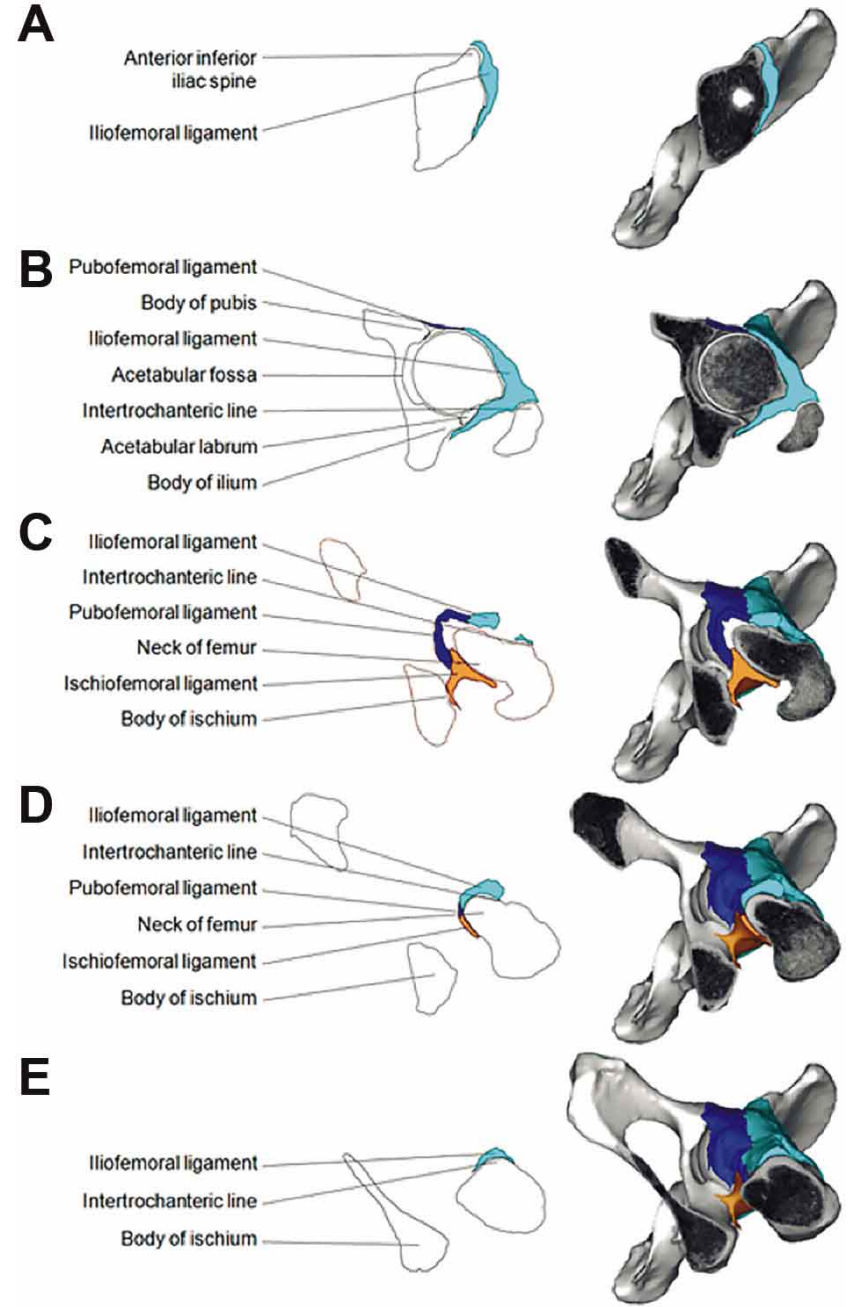

Fig. 5. Outlined images of the hip bone, femur and colorfilled images of the ligaments at the different levels A to E (left column), which are replaced with the sectioned images of the bones accompanied by surface models of the bones and ligaments (right column).

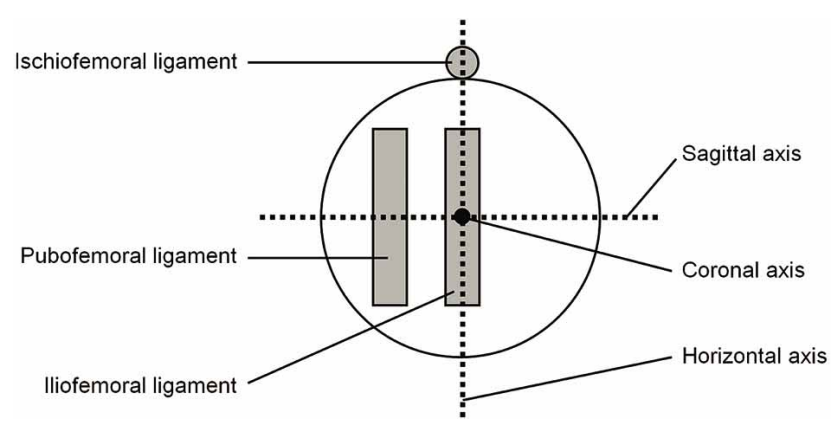

Fig. 6. Schematic illustration of the Cartesian coordinate system passing center of head of femur and the elementary direction of three ligaments in the anterior view of left hip joint. The iliofemoral and pubofemoral ligaments are located anterior to the head, while the ischiofemoral ligament is superior to the head. 


\section{RESULTS}

The sectioned images revealed fine details that were not identifiable in the clinical images, via CTs or MRIs. For example, a nutrient artery entering the neck of femur was observed (Fig. 1A). Remarkable findings with regard to the hip joint of the subject were as follows.

In the horizontal and vertical sectioned images, articular cartilage covering the head of femur as well as the lunate surface of acetabulum was observed. The cartilage looked white which is the natural color in the human body. The cartilage on the center of articular surface was the thickest and it became gradually thin as it went toward the periphery. This was an expected result in consideration of the cartilage role during hip joint movement. Observation of the cartilage thickness disclosed that the center of articular surface was not the fovea of head of femur, an attaching site of ligament of head of femur (Fig. 2).

In the sectioned images, various tissues around the hip joint differed from one another in brightness and texture, depending on their composites and properties. The ligament was darker than the articular cartilage, but brighter than the muscle. Since the ligament is a dense regular connective tissue, its appearance was variable in accordance with the sectional direction (transverse or longitudinal), which was helpful in discrimination of the borders between neighboring ligaments (Fig. 2).

After serial delineation and surface reconstruction, the ligaments and bones were surveyed to confirm the known facts (Moore et al.).

Among three ligaments, the iliofemoral ligament was the largest, succeeded by the pubofemoral and ischiofemoral ligaments successively. The iliofemoral ligament started from the anterior inferior iliac spine, body of ilium, acetabulum (Fig. 3B), divided into the descending and transverse parts, both of which ended at the intertrochanteric line (Fig. 3A). The pubofemoral ligament ran from the obturator crest of pubis and acetabulum to the neck of femur (Fig. 3A). The ischiofemoral ligament connected the body of ischium and acetabulum with the greater trochanter. At the posterior neck of femur, the ischiofemoral ligament included the orbicular zone, thickened articular capsule, since two structures were not well distinguishable during delineation (Fig. 3C). The complicated hip joint could be unusually reviewed with the combined two-dimensional (2D) and 3D images (Fig. 5 ). During hyperextension of hip joint, all three ligaments got extended as anticipated (Fig. 3).
The three ligaments could be schematically represented to elucidate their restriction on the hip joint movement (Fig. 6). In addition, individual muscles were rebuilt thanks to the high-quality sectioned images (Fig. 4). The hip joint motion (Fig. 3) and other figures in this article were recorded in a movie file, which could be downloaded from the Visible Korean homepage (anatomy.co.kr).

\section{DISCUSSION}

The most specific attribute of this inquiry is the precise outlining of the hip joint ligaments in the sectioned images. In spite of the rapid development of clinical images, they don't allow identification of individual ligaments of patients. That is why hip bone and femur on the CTs and MRIs have been intensively analyzed. To overcome the limitation, a cadaver study was performed: After shoulder dissection, researchers inserted metal pins to mark the centroid of the attachment area of each ligament. Then the specimen was scanned using CT to obtain the 3D coordinates of the centroids of the ligamentous attachments. Using the Visible Human Project, bones and muscles of lower limb was segmented and reconstructed. But the report to deal with hip joint ligaments in such sectioned images was not encountered.

The cadaver sectional images allow delineation in plenty, but with difficulty. It is because some information of the images facilitates recognition of a structure, whereas other information interferes with the job. For instance, bones that are distinct in CTs show relatively unclear borders in the sectioned images. It is due to much detail of the neighboring connective tissue. Consequently there is no alternative to the time-consuming drawing work by the researchers with anatomy knowledge (Shin et al., 2012b). It is just favorable that filtering of images promotes the detection of obscure borders (Fig. 1).

Small advantage from the demarcation is that annotations in any sectional planes get easy. The outlined images can be converted into the color-filled images of the horizontal, coronal, and sagittal directions (Park et al., 2009; Shin et al., 2011a). Referring to the colors, labeling on the corresponding sectioned images is performed without more consideration. Not only the outlined structures but also the non-outlined structures (e.g., ligament of head of femur) are conveniently annotated with little knowledge of their location (Fig. 2).

The main effect of outlining is to construct 3D surface models of structures, which are immediately perceived. In 
the present study, the surface models of the hip joint ligaments and neighboring components can be displayed, rotated, sectioned, and even modified. This manipulation of the surface models enhances the comprehension of the shape and role of the ligaments (Figs. 3 and 5). Concerning the 3D models, Mimics is the advantageous software package in three aspects.

First, the Mimics permits more automatized surface reconstruction. In the previous studies, authors used 3DDOCTOR version 4 (Able Software, Corp., Lexington, MA) to make the surface model of every structure, one by one (Jang et al.; Shin et al., 2011a, 2011b, 2012a, 2012b). Unlike the 3D-DOCTOR, Mimics makes it possible to obtain adjoining surface models simultaneously. For this reason, manual process and prejudice by developers are minimized (Lee et al.; Benkhadra et al.; Storck et al.).

Second, the Mimics is capable of production and management of both surface and volume models. The surface models have the definite merit of small file size. However, the surface models themselves, cannot visualize the informative sectional planes. The Mimics shows the valuable planes from the volume models, which are overlapped on the surface models. This kind of exhibition clarifies the stereoscopic arrangement of a structure. A minor drawback is that the sectional plane is not in color but in gray (Fig. 5).

Third, the Mimics software shares the file formats (STL, DXF, VRML, PLY, etc.) with other popular 3D software packages to exchange data back and forth. In this investigation, Mimics is unable to execute joint moving with the constructed surface models (Fig. 3). A solution is to send the 3D models to the fitting software, Maya by way of STL.

We built the 3D surface models showing the real feature of the hip joint ligaments, based on the sectioned images of cadaver (Figs. 3 and 5). Our subsequent interest was the simplification of the structures to acquire a schematic (Fig. 6).

In the schema, main features are the axes of hip joint and the core directions of ligaments. As a ball and socket joint, hip joint has three axes, all of which pass the center of head of femur: Sagittal axis for flexion and extension; coronal axis for adduction and abduction; horizontal axis for medial and lateral rotations (Fig. 6). If a ligament either passes an axis or is parallel to an axis, the ligament has no action about the axis. Instead the ligament plays the limitation role of movement along the other axes.

It was hypothesized that the individual ligaments of hip joint are extremely simple to be vertical or anteroposterior lines: The iliofemoral ligament passes the coronal axis of hip joint, and is parallel to horizontal axis. Therefore, its action is just related with the remaining sagittal axis that is the restriction of hyperextension of hip joint. The ischiofemoral ligament has the same restraint action for other reason that it is passing horizontal axis, and parallel to coronal axis. The pubofemoral ligament, parallel to horizontal axis, is related to both sagittal axis (restriction of hyperextension) and coronal axis (restriction of abduction) (Fig. 6).

Value of the schematic picture (Fig. 6) is raised comparing with the factual 3D models of the ligaments (Figs. 3 and 5). It would also be beneficial to create a similar scheme of hip joint muscles on the basis of their surface models (Fig. 4), because more than 30 muscles moving spheroidal hip joint are too complex to be simply grasped.

In this research, it has been confirmed that hip joint ligaments are definitely identified in the sectioned images and effectively figured out in the surface models. All the 2D and 3D image data are going to be distributed to other interested investigators. The graphic contents hopefully contribute to the development of virtual reality for the medical students' learning and the orthopedic surgeons' clinical trial.

To be more valuable in future, following researches are devised. The sectioned images as well as the surface models of hip joint are placed in a PDF file, where all graphic data are visualized with interactive elements to stimulate creative learning (Shin et al., 2012a, 2012b).

Into the surface models of the hip joint ligaments, biotechnical data are input. Hyperextension and flexion of the models are then simulated to determine the motion range. The angles can be compared with the clinical data of hip joint. Were the assorted motions of ball and socket joint simulated, detailed functions of ligaments could be further analyzed. For example, role difference between descending and transverse parts of the iliofemoral ligament would be visualized and studied by utilizing the technique described.

\section{ACKNOWLEDGMENTS}

This research was supported by Basic Science Research Program through the National Research Foundation of Korea (NRF) funded by the Ministry of Education, Science and Technology (grant number 2010-0009950). Raw data of the Visible Korean were acquired by the financial assistance from the Korea Institute of Science and Technology Information. 
SHIN, D. S.; HWANG, S. B.; PARK, J. S.; PARK, H. S.; LEE, S.; LEE, S-B. \& CHUNG, M. S. Ligamentos de cadera, un estudio cadaverico imagenológico para educación. Int. J. Morphol., 32(3):822-828, 2014.

RESUMEN: La morfología estereoscópica de los ligamentos iliofemoral, pubofemoral e isquiofemoral de la articulación de la cadera es difícil de entender, ya sea a partir de lo hallado en los libros de anatomía como en la disección de cadáveres. Para ayudar en su comprensión, se construyeron modelos tridimensionales a partir de imágenes de secciones cadavéricas de la cadera, que demuestran de mejor manera los componentes finos, en comparación a las imágenes de tomografía axial computada y resonancia magnética nuclear. En los datos obtenidos del "Visible Korean Project", correspondientes a mujeres, los ligamentos de la articulación y sus estructuras vecinas fueron reconocidos y descritos en detalle. Sucesivamente, se identificaron los contornos y se reconstruyeron para la fabricación de modelos de superficie, mediante el uso de un sofisticado método informático. Los modelos de superficie se asociaron con las imágenes de sección originales, que aumentaron la comprensión de la anatomía de la articulación de la cadera. En los modelos de superficie se provocó la hipertensión de la articulación de la cadera para permitir evidenciar la función de los ligamentos. Se espera que los datos gráficos obtenidos de los modelos de superficie de los ligamentos de la cadera sirvan como fuente para el desarrollo de simuladores interactivos que permitan el estudio de la anatomía y la cirugía de la articulación de la cadera.

PALABRAS CLAVE: Articulación de cadera; Ligamentos; Proyectos humanos visibles; Anatomía transversal; Imagenología 3-D.

\section{REFERENCES}

Benkhadra, M.; Savoldelli, G.; Fournier, R.; Gamulin, Z.; François, C.; Trouilloud, P.; Feigl, G. \& Fasel, J. H. A new anatomical technique to investigate nerves by imagery. Surg. Radiol. Anat., 31(3):221-4, 2009

Hwang, S. B.; Chung, M. S.; Hwang, Y. I.; Park, H. S.; Har, D. H.; Shin, D. S.; Shin, B. S. \& Park, J. S. Improved sectioned images of the female pelvis showing detailed urogenital and neighboring structures. Korean J. Phys. Anthropol., 23(4):187-98, 2010.

Jang, H. G.; Chung, M. S.; Shin, D. S.; Park, S. K.; Cheon, K. S.; Park, H. S. \& Park, J. S. Segmentation and surface reconstruction of the detailed ear structures, identified in sectioned images. Anat. Rec. (Hoboken), 294(4):559-64, 2011.

Lee, Y. S.; Seon, J. K.; Shin, V. I.; Kim, G. H. \& Jeon, M. Anatomical evaluation of CT-MRI combined femoral model. Biomed. Eng. Online, 7: 6, 2008.

Moore, K. L.; Dalley, A. F. \& Agur, A. M. R. Clinically Oriented Anatomy. 7th ed. Philadelphia, Wolters Kluwer/Lippincott Williams \& Wilkins, 2014.

Park, J. S.; Chung, M. S.; Hwang, S. B.; Lee, Y. S. \& Har, D. H. Technical report on semiautomatic segmentation using the Adobe Photoshop. J. Digit. Imaging, 18(4):333-43, 2005.

Park, J. S.; Chung, M. S.; Shin, D. S.; Har, D. H.; Cho, Z. H.; Kim, Y. B.; Han, J. Y. \& Chi, J. G. Sectioned images of the cadaver head including the brain and correspondences with ultrahigh field 7.0 T MRIs. Proc. IEEE, 97(12):1988-96, 2009.

Park, J. S.; Jung, Y. W.; Lee, J. W.; Shin, D. S.; Chung, M. S.; Riemer, M. \& Handels, H. Generating useful images for medical applications from the Visible Korean Human. Comput. Methods Programs Biomed., 92(3):257-66, 2008.

Park, J. S.; Shin, D. S.; Chung, M. S.; Hwang, S. B. \& Chung, J. Technique of semiautomatic surface reconstruction of the visible Korean human data using commercial software. Clin. Anat., 20(8):871-9, 2007
Shin, D. S.; Chung, M. S.; Park, J. S.; Park, H. S.; Lee, S. B.; Lee, S. H.; Choi, H. N.; Riemer, M.; Handels, H.; Lee, J. E. \& Jung, W. Three-dimensional surface models of detailed lumbosacral structures reconstructed from the Visible Korean. Ann. Anat., 193(1):64-70, 2011a.

Shin, D. S.; Chung, M. S.; Lee, J. W.; Park, J. S.; Chung, J.; Lee, S. B. \& Lee, S. H. Advanced surface reconstruction technique to build detailed surface models of the liver and neighboring structures from the Visible Korean Human. J. Korean Med. Sci., 24(3):375$83,2009 a$.

Shin, D. S.; Park, J. S.; Lee, S. B.; Lee, S. H.; Chung, J. \& Chung M. S. Surface model of the gastrointestinal tract constructed from the Visible Korean. Clin. Anat., 22(5):601-9, 2009b.

Shin, D. S.; Chung, M. S. \& Park, J. S. Systematized methods of surface reconstruction from the serial sectioned images of a cadaver head. J. Craniofac. Surg., 23(1):190-4, 2012a.

Shin, D. S.; Park, J. S.; Park, H. S.; Hwang, S. B. \& Chung, M. S. Outlining of the detailed structures in sectioned images from Visible Korean. Surg. Radiol. Anat., 34(3):235-47, 2012 b.

Shin, D. S.; Park, J. S.; Shin, B. S. \& Chung, M. S. Surface models of the male urogenital organs built from the Visible Korean using popular software. Anat. Cell. Biol., 44(2):151-9, 2011 b.

Storck, C.; Juergens, P.; Fischer, C.; Haenni, O.; Ebner, F.; Wolfensberger, M.; Sorantin, E.; Friedrich, G. \& Gugatschka, M. Three-dimensional imaging of the larynx for pre-operative planning of laryngeal framework surgery. Eur. Arch. Otorhinolaryngol., 267(4):557-63, 2010.

Correspondence to:

Dr. Min Suk Chung

Department of Anatomy

Ajou University School of Medicine

164 Worldcup-ro

Suwon, 443-380

REPUBLIC OF KOREA

Received: 09-05-2014 Accepted: 07-07-2014

Email: dissect@ajou.ac.kr 